\title{
M anejo clínico do primeiro episódio psicótico
}

M ario R Louzã Neto

Projeto Esquizofrenia (Projesq) do Instituto de Psiquiatria do HC da FMUSP.

\section{Introdução}

O primeiro episódio oferece uma oportunidade única no tratamento da esquizofrenia. Sabe-se hoje que a doença, e possivelmente também a deterioração, começa vários anos antes das manifestações floridas. ${ }^{1} \mathrm{O}$ longo período prodrômico que antecede a procura por tratamento caracteriza-se por sintomas inespecíficos, tais como dificuldade de atenção e concentração, insônia, ansiedade, isolamento social e irritabilidade. ${ }^{2}$ Estudos mostram que a demora na procura do tratamento tem uma influência fundamental no prognóstico do paciente. Muitas vezes o período entre o início dos sintomas prodrômicos e o início do tratamento chega a durar vários meses ou anos. Isso ocorre durante um período em que o jovem está estudando ou iniciando sua vida profissional, levando a uma ruptura significativa de sua rede social. ${ }^{3} \mathrm{O}$ tempo de tratamento para obtenção da remissão também aumenta à medida que se sucedem os episódios psicóticos.

É fundamental que o primeiro episódio seja tratado de modo incisivo e eficaz para minimizar o risco de uma má evolução da esquizofrenia. ${ }^{4}$

\section{Manejo clínico}

Os primeiros passos no manejo clínico do primeiro episódio são a avaliação inicial e o diagnóstico diferencial da psicose. No diagnóstico diferencial devem ser considerados os transtornos psicóticos de base orgânica, incluindo as psicoses relacionadas às condições médicas gerais e às psicoses por drogas, os quadros psicóticos afetivos (mania ou depressão psicóticas), as psicoses agudas transitórias e outros. A avaliação inicial inclui, além dos exames físico e neurológico completos, exames laboratoriais e radiológicos para excluir possíveis causas orgânicas. ${ }^{5,6}$

$\mathrm{O}$ tratamento farmacológico e as abordagens psicossociais devem ser implementados simultaneamente.

\section{Tratamento farmacológico}

Os antipsicóticos (AP) de nova geração vêm gradualmente substituindo os antipsicóticos tradicionais no tratamento do primeiro episódio psicótico devido à sua ação terapêutica mais abrangente e à menor incidência de efeitos colaterais. São hoje, com exceção da clozapina, as medicações de primeira escolha no tratamento da esquizofrenia. Pacientes de primeiro episódio necessitam, de modo geral, de doses mais baixas de AP do que pacientes crônicos. Estudos de
PET (tomografia por emissão de pósitron) mostram que baixas doses de AP são suficientes para bloquear adequadamente os receptores implicados na esquizofrenia. ${ }^{7,8}$ Devido à latência para início do efeito antipsicótico, é preciso aguardar pelo menos por 6-8 semanas antes de considerar a ausência de resposta à medicação. Para o controle de sintomas como ansiedade, insônia ou agitação podem ser indicados benzodiazepínicos, utilizados por curto período de tempo.

A principal limitação dos AP de nova geração é a ausência, até o momento, de apresentação injetável, tanto para casos agudos, como na forma "depot", para tratamento de manutenção. $\mathrm{O}$ efeito colateral mais importante tem sido o ganho de peso, que deve ser monitorado constantemente. ${ }^{9}$

Se o paciente não responde ao primeiro AP de nova geração, deve-se substituí-lo por um segundo AP de nova geração. Se persistir a ausência de resposta, pode-se utilizar um terceiro AP de nova geração ou um AP clássico, se o paciente não tiver história prévia de ausência de resposta a essas drogas. Em seguida, está indicado o uso de clozapina, seguindo-se as normas habituais de controle hematológico do paciente. $\mathrm{Na}$ ausência de resposta a clozapina ou impossibilidade de seu uso, estão indicados a eletroconvulsoterapia (ECT), a combinação de AP, e a potencialização com outros medicamentos (especialmente estabilizadores do humor e antidepressivos). ${ }^{10}$ Diferentes grupos de experts têm proposto algoritmos para o tratamento do primeiro episódio: alguns propõem apenas o uso de antipsicóticos de nova geração e clozapina, outros consideram a possibilidade de uso de antipsicóticos tradicionais em circunstâncias específicas, mas sempre após a utilização dos novos antipsicóticos. ${ }^{11,12}$ (Figura)

Uma vez controlado o episódio agudo, segue-se o tratamento de manutenção para evitar recaídas ou novas crises. Conforme a evolução clínica do paciente, é possível reduzir gradualmente a dose do antipsicótico, em geral até cerca de $50 \%$ daquela utilizada durante a crise. O uso da menor dose efetiva é importante para, ao mesmo tempo, garantir o efeito profilático da medicação e minimizar os efeitos colaterais.

A duração do tratamento de manutenção é também fundamental, pois se sabe que cerca de $75 \%$ dos pacientes sofrem recaída em um período de 24 meses após a suspensão da medicação. Embora não haja um consenso na literatura, sugerese que os pacientes sejam mantidos continuamente com medicação antipsicótica por pelo menos dois anos após o primeiro 


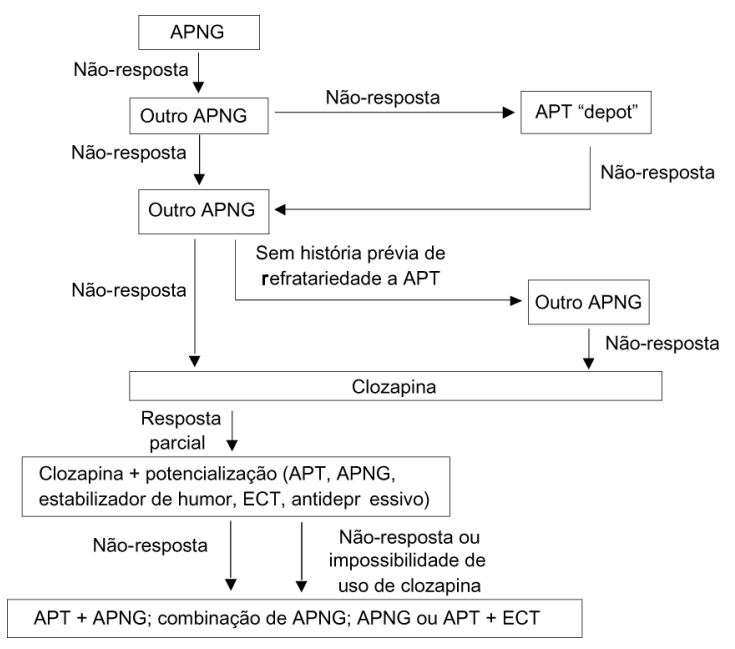

Legenda:

APNG = antipsicótico de nova geração;

APT = antipsicótico tradicional;

ECT = eletroconvulsoterapia

(Adaptado de Shon et al; 1999) $^{11}$

Figura - Algoritmo para tratamento farmacológico de primeiro episódio de esquizofrenia

episódio, antes de se cogitar a suspensão da mesma. A orientação sobre o risco de recaída e os sintomas prodrômicos favorecem a intervenção precoce em caso de reagudização. ${ }^{13,14}$

\section{Abordagens psicossociais}

Para a maioria dos pacientes, o tratamento domiciliar é o mais recomendado, pois evita o afastamento do meio familiar. Eventualmente será preciso internar o paciente durante o quadro agudo, devido ao risco de auto ou heteroagressividade. No entanto, a internação deve ser restrita a essas situações e deve ter a menor duração possível. ${ }^{\mathbf{1 3}}$

O engajamento do paciente e de seus familiares é fundamental desde o início do tratamento. O primeiro episódio tem um impacto muito grande, gerando sentimentos de culpa, negação e perplexidade. Diante dos preconceitos ligados às doenças mentais, o diagnóstico muitas vezes é recebido com ceticismo e até raiva. Estabelecer uma aliança terapêutica é condição básica para o sucesso das intervenções psicossociais. Essas abordagens têm como objetivos: a) prover informações sobre a doença e seu tratamento; b) auxiliar na adaptação à nova condição imposta pela doença; c) promover a adesão ao tratamento medicamentoso; d) reduzir os fatores de risco, tais como abuso de drogas, depressão e suicídio; e) adequar as expectativas em relação ao paciente; f) estabelecer metas realistas para o futuro; g) auxiliar a lidar com situações de estresse; h) adequar atitudes dos familiares, procurando reduzir expressões de crítica, de hostilidade e de superenvolvimento emocional; e i) orientar sobre sintomas prodrômicos de recaída. ${ }^{2}$

Vários procedimentos, como psicoterapia individual ou de grupo, orientação familiar, terapia ocupacional, acompanhamento terapêutico, entre outros, contribuem para a recuperação do paciente e sua reintegração ao âmbito familiar e social. ${ }^{15}$

\section{Conclusão}

A detecção e a intervenção precoces no primeiro episódio psicótico são fundamentais para diminuir a possibilidade de deterioração na esquizofrenia. O tratamento farmacológico deve ser incisivo e a ele se associando as abordagens psicossociais para auxiliar na reintegração do paciente.

\section{Referências}

1. Häfner H, Riecher-Rössler A, Maurer K, Fätkenheuer B, Löffler W. First onset and early symptomatology of schizophrenia. A chapter of epidemiological and neurobiological research into age and sex differences. Eur Arch Psychiatry Clin Neurosci 1992;242(2-3):109-18.

2. McGorry PD, Jackson HJ. The recognition and management of early psychosis: a preventive approach. Cambridge: Cambridge University Press; 1999.

3. DeQuardo JR. Pharmacologic treatment of first-episode schizophrenia: early intervention is key to outcome. J Clin Psychiatry 1998;59Supl 19:9-17.

4. Louzã Neto MR, Motta T, Wang YP, Elkis H. Psiquiatria Básica. Porto Alegre: Editora Artes Médicas; 1995.

5. Sheitman BB, Lee H, Strauss R, Lieberman JA. The evaluation and treatment of first-episode psychosis. Schizophrenia Bull 1997;23(4):653-61.

6. Kapur S, Zipursky RB, Remington G. Clinical and theoretical implications of 5-HT2 and D2 receptor occupancy of clozapine, risperidone, and olanzapine in schizophrenia. Am J Psychiatry 1999;156(2):286-93.
7. Zhang WJ, Zipursky RB, Beiser M, Bean G. Optimal haloperidol dosage in first-episode psychosis. Can J Psychiatry 1999;44(2):164-7.

8. Baptista T. Body weight gain induced by antipsychotic drugs: mechanisms and management. Acta psychiatr Scand 1999;100:3-16.

9. Remington G, Kapur SK, Zipursky RB. Pharmacotherapy of firstepisode schizophrenia. Brit J Psychiatry 1998;172Supl 33:66-70.

10. Collaborative Working Group on Clinical Trial Evaluations. Treatment of special populations with the atypical antipsychotics. J Clin Psychiatry 1998;59Supl 12:46-52.

11. Shon SP, Crismon ML, Toprac MG, Trivedi M, Miller AL, Suppes $\mathrm{T}$ et al. Mental health care from the public perspective: the Texas medication algorithm project. J Clin Psychiatry 1999;60Supl 3:16-20.

12. Wyatt RJ, Damiani LM, Henter ID. First-episode schizophrenia. Early intervention and medication discontinuation in the context of course and treatment. Brit J Psychiatry 1998;172Supl 33:77-83

13. Louzã Neto MR, Elkis H, editors. Esquizofrenia: abordagem atual. São Paulo: Lemos Editorial; 1999.

\section{Correspondência: Mario R Louzã Neto}

Instituto de Psiquiatria HC-FMUSP

Projesq - Rua Ovídio Pires de Campos, s/ $\mathrm{n}^{\circ}, 3^{\circ}$ andar

05403-010 São Paulo, SP. 